Neth. J. Agric. Sci., 15 (1967) : 170-182

\title{
Entrance resistance of plastic drain tubes
}

\author{
J. Wesseling and F. Homma
}

Institute for Land and Water Management Research (I.C.W.), P.O. Box 35, Wageningen, The Netherlands

Received 12 August, 1966

\section{Summary}

The entrance resistance of plastic drain pipes with various amounts of longitudinal slits and covered with certain filter materials has been measured in a vertical sand tank model. It became apparent that the influence of an increasing amount of perforations on the lowering of the entrance resistance lessens at high perforation amounts. In general, a decrease of the entrance resistance can be better obtained by means of larger pipe diameters than by increasing the amount of perforations. For practical applications, a $4 \mathrm{~cm}$ pipe with 1 sheet of glass fibre requires about $450 \mathrm{~mm}^{2}$ of perforations per running meter.

The application of a single sheet of glass fibre has already a very favorable effect on the entrance resistance of the drains. This effect has to be ascribed to the development of a more permeable layer rather than to its effect as a filter. Increasing the thickness of the filter (assuming it will retain its high permeability under field conditions) will be more effective in decreasing the entrance resistance than increasing the pipe diameter.

Some examples from practice show that, with the use of $4 \mathrm{~cm}$ pipes having 2 rows or $450 \mathrm{~mm}^{2}$ of longitudinal slit perforations and covered with one sheet of glass fibre, the extra loss of head due to the entrance resistance is in most cases negligible. Only when the hydraulic conductivity of the backfill of the trench is low (about $10 \mathrm{~cm}$ / day) this will not be the case. In such circumstances it is advisable to use a thicker filter or a larger pipe diameter.

\section{Introduction}

In The Netherlands each year some 20,000 ha of agricultural land are drained by means of subsurface drainage systems. An extensive description of the methods and materials used is given by van Someren (1964). At present about one third of the pipe material consists of rigid P.V.C. Since the introduction of this material in 1959 some $15,000 \mathrm{~km}$ have been laid all over the country.

Plastic pipes must be provided with perforations to let the water enter. Then amount, type and size do not only determine the rate of inflow but also influence the strength of the pipes.

The entrance resistance of a drain tube may be defined as an additional loss of head caused by the partial permeahility of its wall. To obtain a low entrance resistance a large amount of perforations is required. This will often weaken the pipe to such an extent that a larger wall thickness is required to make it withstand the load of 
the backfill of the trench. Since there is a close relationship between the price of the pipe and its wall thickness, the smallest possible amount of perforations must be used to obtain the cheapest pressure-resistant pipes.

Good permeable filter material will on the other hand decrease the entrance resistance considerably, as is the case when taking a larger diameter. Now the main question is, what combination of perforation, filter material and pipe diameter to take.

On request of the Government Service for Land and Water Use (The Netherlands), model tests on several types of plastic pipes have been carried out. The main purpose of these tests was to investigate which factors do determine the entrance resistance and to what extent. This research must be considered more as an addition to, than as a substitute for field tests.

\section{Previous investigations}

For clay pipes several theories about the entrance resistance have been developed, for example by Engelund (1953), Ernst (1954, 1962), Kirkham (1950) and Kozeny (1933). According to Ernst (1962) the results of these theories only slightly differ and can all be represented by the equation:

$$
w_{e}=\frac{a}{K}
$$

where $w_{e}$ is the entrance resistance (day/m), $K$ is the hydraulic conductivity $(\mathrm{m} /$ day) of the soil surrounding the pipe and $a$ is a factor ranging from 2 to 2.5 .

According to computations carried out by van der Beken (1962), $a$ can range from 0.85 to 2.48 depending on what assumptions are made by the theories of the above mentioned authors. From model tests de Jager (1960) found $a \approx 0.9$.

From equation 1 it follows that the hydraulic head $(m)$ due to the entrance resistance is:

$b_{e}=a \frac{Q L}{K}$

where $Q$ is the discharge of the drainage system $(\mathrm{m} /$ day) and $L$ is the drain spacing $(\mathrm{m})$. The hydraulic head required for a flow $Q$ towards a drainage system in a homogeneous soil is given by Hooghoudt (1940) as:

$\triangle h=\frac{Q L^{2}}{8 K d}$

where $d$ is the depth of the 'equivalent layer' (m). Following Ernst (1954) we get from equation 2 and 3 :

$\frac{\triangle h}{b_{e}}=\frac{L}{8 a d}$

For a drain spacing of $15 \mathrm{~m}$ and $d=2 \mathrm{~m}$ we find for $a=1$ an entrance resistance that is of the same magnitude as the rest of the flow resistance in the remainder 
of the region of flow. Therefore the entrance resistance can only be neglected when the hydraulic conductivity of the backfill is relatively large as compared with that of the undisturbed soil. Equation 4 points out that the use of filter material in drainage is of the utmost importance when the hydraulic conductivity of the backfill is low.

Kirkham and Schwab (1951) give a theory for the effect of circular perforations in flexible polyaethylene tubes. Engelund (1953) gives a theory for circular openings as well as for circumferential slits. For the latter van der Beken (1962) computed $a$-values of $1.5-1.8$ for a $0.04 \mathrm{~cm}$ slit.

The pipes normally used in The Netherlands are provided with 2-4 rows of longitudinal slits having a length of $26 \mathrm{~mm}$ and a width of approx. $0.6 \mathrm{~mm}$. The above mentioned theories are therefore not applicable to these pipes and the only way out is performing model tests.

Wesseling (1959) carried out some tests in a sand tank of $260 \times 150 \times 40 \mathrm{~cm}$. The values of the entrance resistance were obtained by measuring the total resistance in the neighbourhood of the drain and diminishing this value with the radial resistance of an ideal drain. For the latter, a drain pipe with a large amount of perforations was used. For polyaethylene tubes with circumferential slits of $12.5 \times 0.5 \mathrm{~mm}, a$ values of $0.2-1.2$ were found dependent on the amount of slits.

De Jager (1960) and van der Beken (1962) carried out tests in a sand tank of $200 \times$ $120 \times 100 \mathrm{~cm}$. These authors assumed that the total measured resistance was given by the equation:

$b_{t}=Q L w_{r}+Q L w_{e}$

where $h$, is the total hydraulic head $(\mathrm{m}), w_{r}$ the radial resistance (day/m) and $w_{e}$ the entrance resistance $(\mathrm{day} / \mathrm{m})$. The first part of the right hand member of equation 5 was computed from Ernst's equation:

$w_{r}=\frac{1}{\pi K} \ln \frac{D}{\pi r}$

where $D$ is the depth (m) of the water bearing layer and $r$ is the radius of the pipe (m). The authors concluded that only the length and amount of perforations determine the entrance resistance. Both the width of the slits and the number of rows had little or no influence; for the diameter of the pipe a small negative influence was found.

The above mentioned tests were carried out in one type of sand. Boumans (1963) carried out tests in a cylindrical model and used two types of sands with hydraulic conductivities of $6-9 \mathrm{~m} /$ day and $2-3 \mathrm{~m} /$ day, respectively. He concluded that in finer material a relatively smaller entrance resistance will occur due to the fact that in such soils the finer particles are washed out, resulting in a larger permeability in the neighbourhood of the perforations. Furthermore, glass fibre was found to have a favourable effect, increasing with finer sands. He found $a$-values ranging from 0.002 to 0.35 for different types of pipes and filter material. Due to the use of a different model, these values are not entirely comparable with those found from a horizontal model.

\section{Description of the model used}

Since a large number of investigations had to be carried out, the big model described 


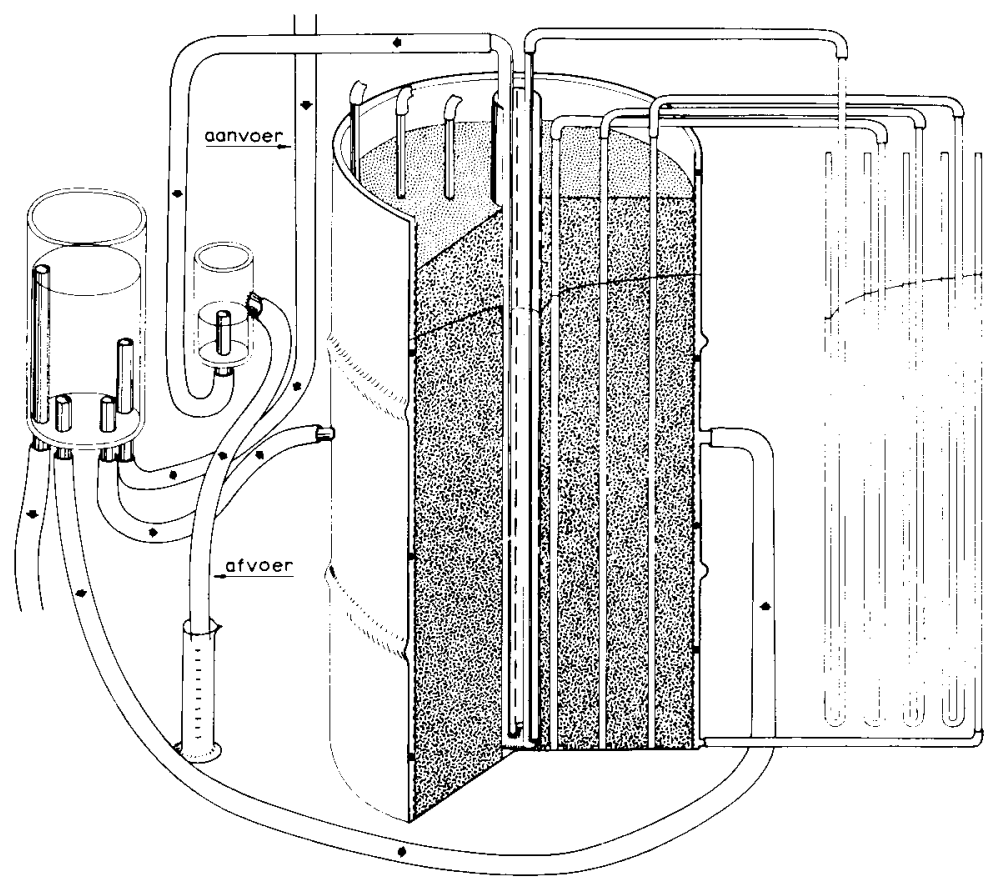

Fig. 1 Scheme of the model used.

by Wesseling (1959) was not used. Based on the results obtained by Boumans (1963), a new model was developed (Fig. 1). The flow models consist of an oil drum of 501 with a diameter of $36 \mathrm{~cm}$ and a height of $60 \mathrm{~cm}$. Inside the drum a cylinder, made from a brass sheet with perforations of $2 \mathrm{~mm}$ diameter, with a diameter $0.5 \mathrm{~cm}$ smaller than that of the drum is placed, and covered at the inside with a sheet of glass fibre. The pipes to be investigated are fixed to the bottom at the centre of the model by means of a $1 \mathrm{~cm}$ high iron ring.

After placing the drain pipe and some 6-10 piezometer pipes in a row across the drum, the drum is filled with moist sand. In order to get a more homogeneous filling the sand was not wetted through and through. Three types of sand, having a hydraulic conductivity of approx. $1 \mathrm{~m} /$ day, $10 \mathrm{~m} /$ day and $100 \mathrm{~m} /$ day, respectively, were used.

The piezometer pipes, consisting of $6 \mathrm{~mm}$ brass tubes, have a perforation of approx. $1 \mathrm{~cm}$ length at a height of $29 \mathrm{~cm}$ above the bottom of the drum. They are connected with water manometers, as indicated in Fig. 1.

After installation of the drain pipe a syphon is lowered into it. A constant water level is maintained between the wall of the drum and the screen at $0.5 \mathrm{~cm}$ distance, and in the drain pipe by means of two small overflow systems. By changing the head of the overflow systems, the flow intensity can be varied. In order to avoid growth of algae, hypochloride (in a concentration of $1 \mathrm{~cm}^{3}$ per liter) was added to the tapwater used. 


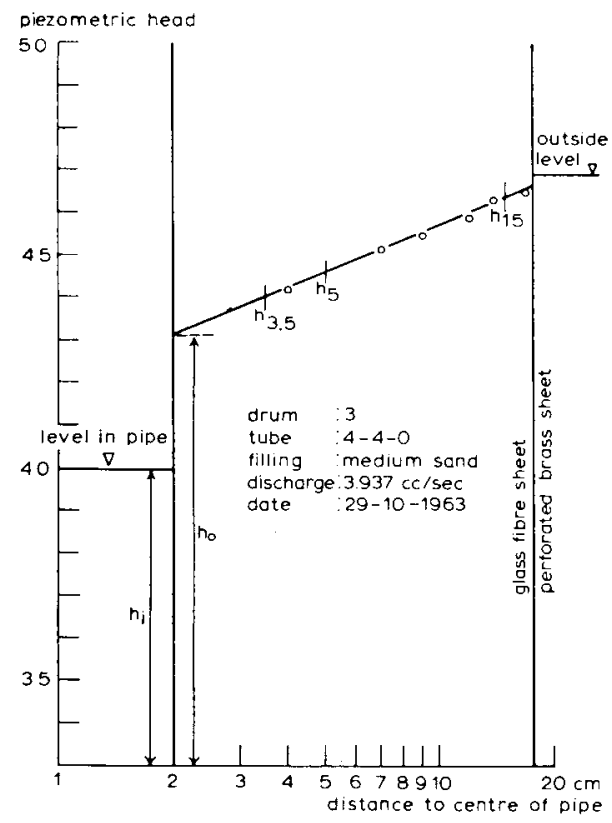

Fig. 2 Relationship between the piezometric head (cm) and the logarithm of the distance to the centre of the pipe in the model.

\section{Computation of the entrance resistance}

The flow in the model can be characterized as the flow towards a well in a phreatic aquifer, thus:

$Q=\frac{\pi K\left(h_{2}^{2}-h_{1}^{2}\right)}{\ln r_{2} / r_{1}}$

where $Q$ is the discharge, $h_{1}$ and $h_{2}$ are the piezometric heads measured at distances of $r_{1}$ and $r_{2}$, respectively from the centre of the well. A necessary condition for the flow is that:

$\frac{h_{2}-h_{1}}{r_{2}-r_{1}}<\frac{1}{2}$

As long as this condition is fulfilled, the piezometric head will show a linear relationship with the logarithm of the distance (Fig. 2). From the slope of the line obtained in this way, the hydraulic conductivity of the filling can be computed. For $h_{1}$ and $h_{2}$, neither the water level outside the soil body nor that in the drain pipe can be used. Since the perforated brass cylinder is covered with a sheet of glass fibre in order to avoid soil penetrating into the openings, there can be a certain loss of head due to possible clogging of the glass fibre. The level inside the pipe can not be used since it is dependent on the entrance resistance of the pipe. Furthermore there will always be a certain surface of seepage, above the water level in the pipe.

The entrance resistance of the pipe can be computed from the water level inside 
the pipe $h_{i}$, the piezometric pressure outside the pipe $h_{o}$ and the flow per unit length of pipe $Q / h_{i}$, so from:

$w_{e}=\frac{b_{\mathrm{o}}-h_{i}}{Q / h_{i}}$

Due to the surface of seepage there will always be a small underestimation of $h_{i}$. The value of $h_{\mathrm{o}}$ must be found from the adjusted line of Fig. 2, since piezometers can not be placed close to the pipe as in the neighbourhood of the perforations the flow will no longer be purely horizontal and readings would be affected by other flow components.

In order to be able to compare resistance values of pipes with various diameters the following formula was used:

$w=\frac{h_{3.5}-h_{i}}{Q / h_{i}}=\frac{\triangle h_{3.5} h_{i}}{Q}$

where $h_{3.5}$ is the piezometric pressure at $3.5 \mathrm{~cm}$ from the centre of the pipe, as the largest pipe diameter used was $7 \mathrm{~cm}$. For the latter case the resistance is of course equal to the entrance resistance according to equation 9.

\section{Results of the measurements}

\section{Influence of time}

All the investigations have been carried out with pipes covered with at least one sheet of glass fibre. It may be assumed that when using a filter material, the entrance resistance will increase with time, two tests have therefore been carried out to find this influence. For this purpose a $4 \mathrm{~cm}$ pipe covered with one sheet of glass fibre was placed in coarse sand for 6 months. In one test a continuous flow was maintained during that time. In a second test intermittent flow was applied. The results of both tests are given in Fig. 3. The upper line gives the result for continuous flow. At the end of the experiment the flow direction was changed from inward to outward. This gave a sudden drop in resistance. After changing the flow direction again, an increase in resistance took place immediately and after 10 days the original value was obtained again.

The second line from the top line gives the results for intermittent flow. Dotted parts indicate periods of inverse flow. After having stopped the flow generally a fall in the resistance was observed.

During the experiments the hydraulic conductivity of the soil slightly decreased. The resistance in the $1.5 \mathrm{~cm}$ of soil around the pipe is given in the lower curves. Subtracting this resistance from the earlier mentioned curves would give the actual course of the resistance of the pipe and its filter system. The shape of the upper lines will not be much affected.

The increase in resistance must be mainly ascribed to flocculation of iron present in the tap-water. It seems that after a certain period of continuous flow the Fe-concentration is that large that flocculation occurs and as a consequence the resistance increases. The lower resistance found with intermittent flow may have been caused 


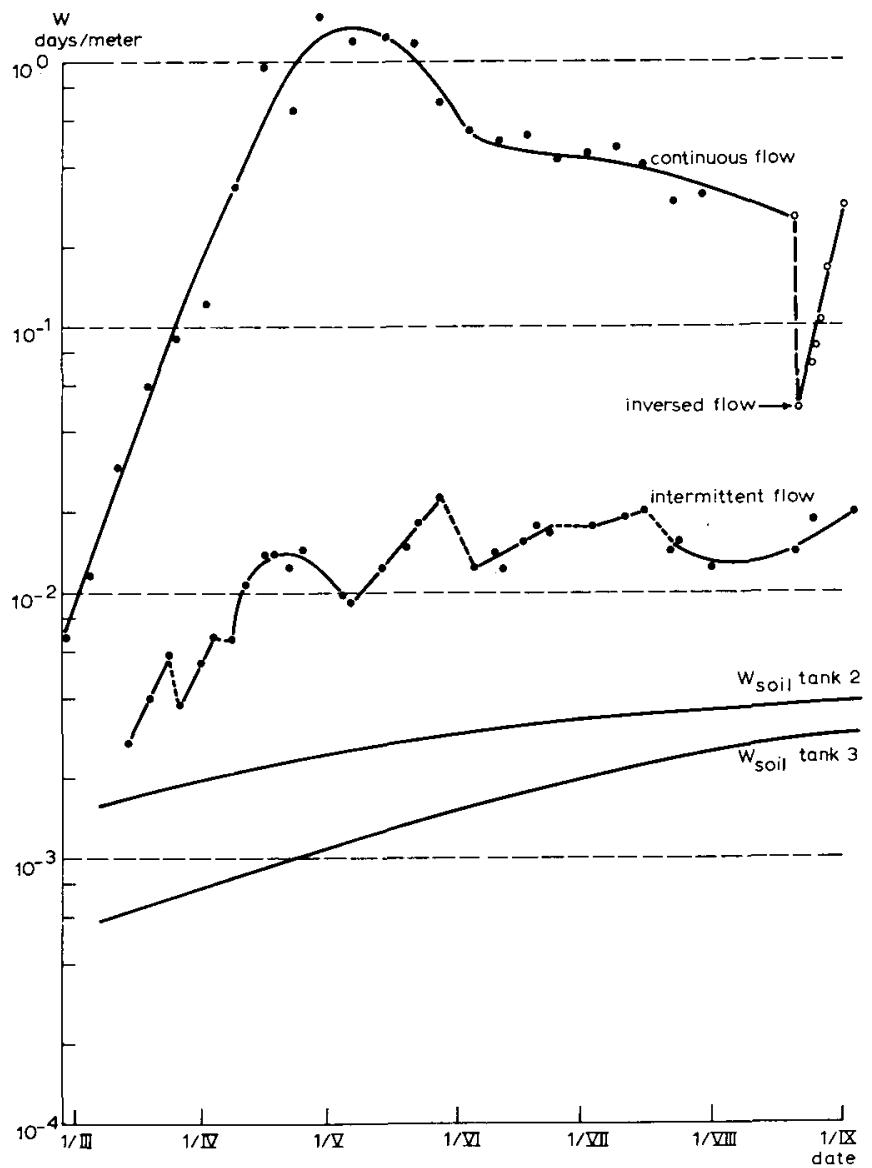

Fig. 3 Course of the entrance resistance (w) for a $4 \mathrm{~cm}$ pipe with a filter consisting of one sheet of glass fibre and of the resistance $w_{\text {soil }}$ of the $1.5 \mathrm{~cm}$ of soil around the pipe.

by the drying-out of the iron deposits during periods of zero flow and their removal when the flow starts again.

In practice always intermittent flow will occur. The increase in resistance will therefore generally not be high, except in cases where seepage causes a continous flow. There will be an increase in resistance in the models, however. All further measurements have therefore been carried out after a period of three days of flow. Each experiment was finished after 5 days, so that no data for periods longer than 5 days of flow have been used. The resistances which will occur in practice may be somewhat higher than those found during the tests, but the purpose of the tests was to make possible comparisons of various pipes and filter material, rather than give absolute values of the final resistance of a certain drainage system in practice.

\section{Influence of perforation}

Fig. 4 gives the results of the computed $w_{e}$-values (equation 9) of various $4 \mathrm{~cm}$ pipes 


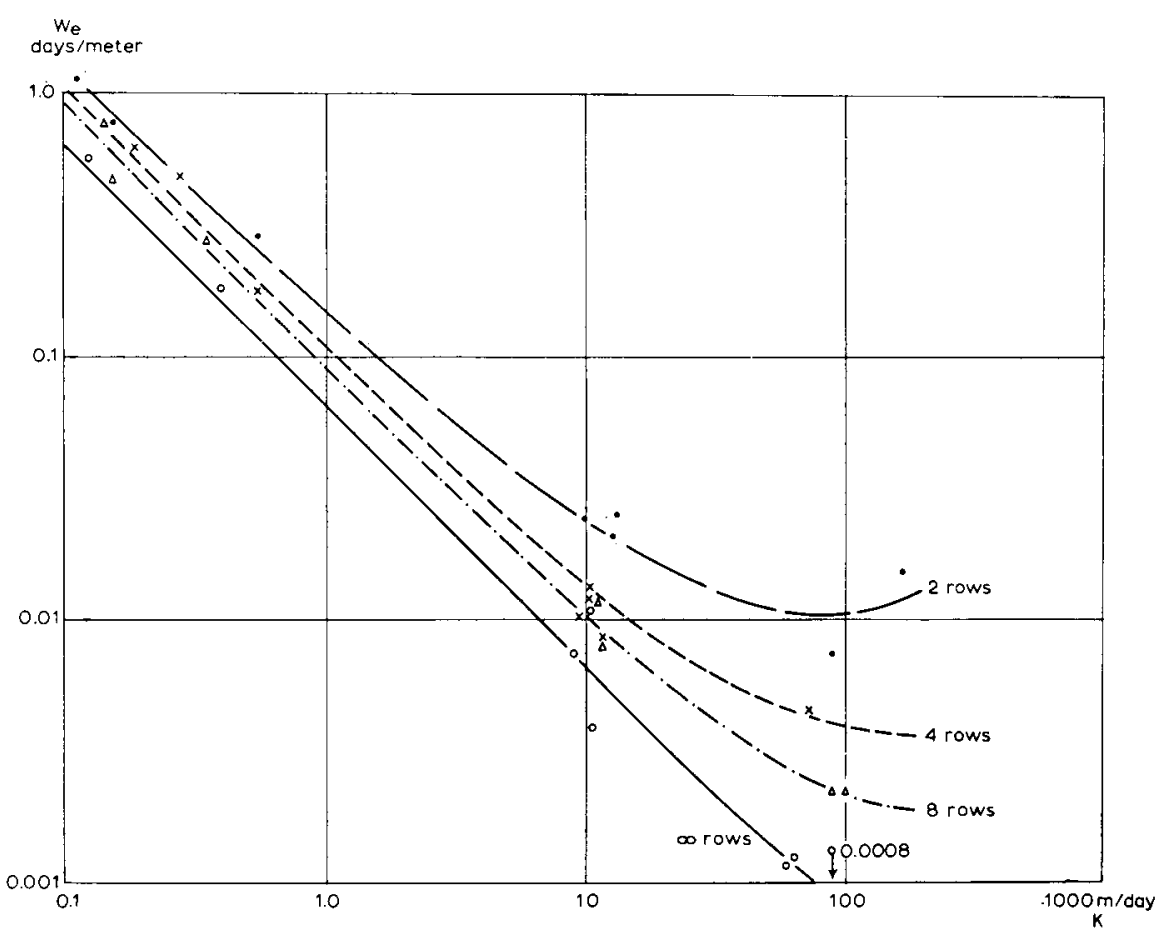

Fig. 4 Values of $w_{e}$ for a $4 \mathrm{~cm}$ pipe with one sheet of glass fibre and various rows of perforations in dependence of the hydraulic conductivity $K$ of the soil.

(with 1 sheet of glass fibre) with different numbers of rows of perforations. Each row had 15 perforations per meter and each perforation had an area of $25 \times 0.6 \mathrm{~mm}$ $=15 \mathrm{~mm}^{2}$. Thus 2 rows of perforations gave $2 \times 15 \times 15 \mathrm{~mm}^{2}=450$ open $\mathrm{mm}^{2}$ per running meter. The points in the figure represent all means of $3-5$ observations. There is an increase in entrance resistance with decreasing amounts of perforations. Towards higher hydraulic conductivities the relative decrease of the entrance resistance becomes somewhat smaller. This may be due to the fact that in this region the hydraulic conductivity of the sand approximates that of the glass fibre. A second reason can be that the flow velocity is that high that turbulent flow occurs in the surroundings of the pipe. It will further be noted that the deviation from the curve is here somewhat larger. This is due to the inaccuracy in the piezometer measurements. Due to the large hydraulic conductivity of the fill, the differences in piezometric head generally are very small.

\section{Influence of diameter}

Fig. 5 gives the results with various pipe diameters. In this case w-values (equation 10) are used for comparison purposes, as explained earlier. For the larger diameters there was only a small influence of the number of perforations. The large deviations of the points from the lines must be partly ascribed to the smaller accuracy with which the piezometric pressure at $3.5 \mathrm{~cm}$ could be obtained. For $5 \mathrm{~cm}$ pipes the 


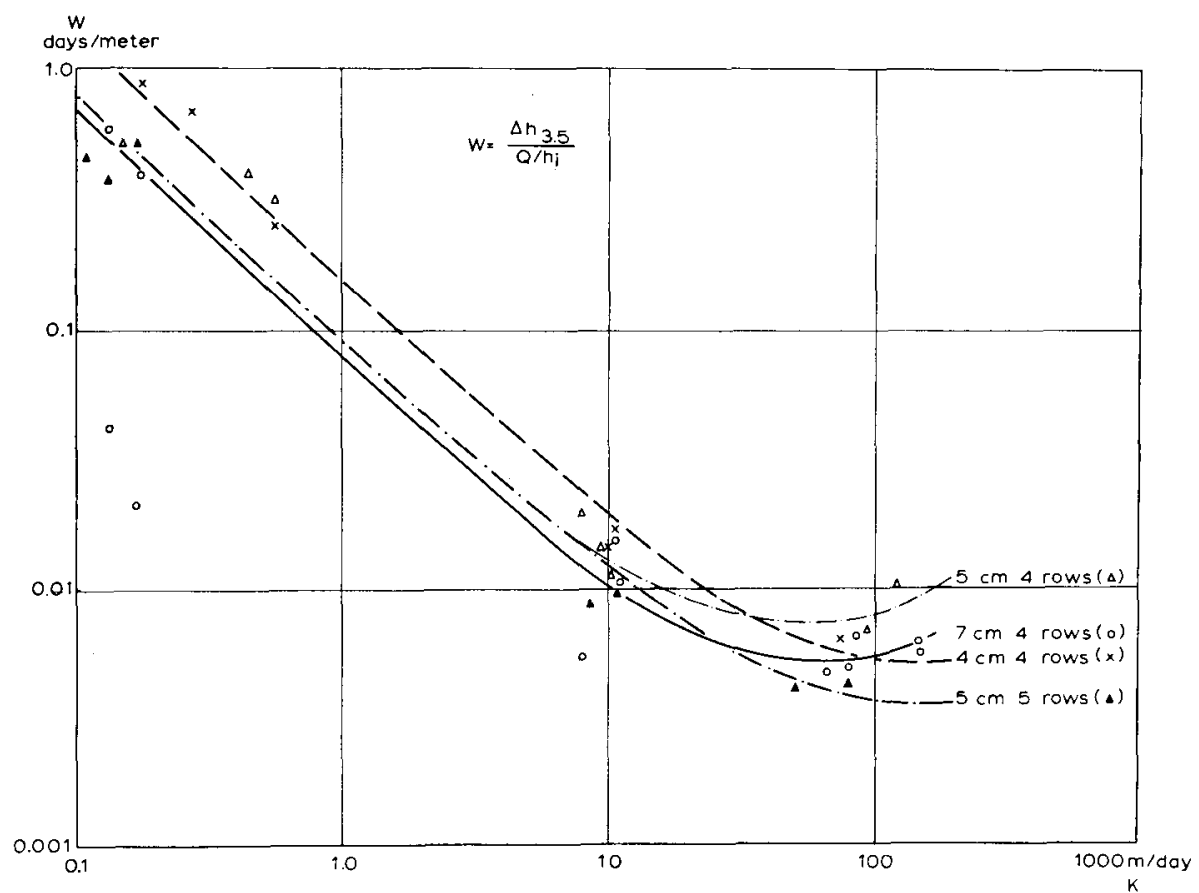

Fig. 5 Values of $w$ for drain pipes with different diameters all with a filter consisting of one sheet of glass fibre for various $K$-values of the soil.

nearest piezometer was at $3.5 \mathrm{~cm}$ and was already affected by disturbances in the neighbourhood of the perforations. The value $h_{3.5}$ of $7 \mathrm{~cm}$ pipes had to be obtained by extrapolation.

\section{Influence of filter material}

Fig. 6 gives the results ( $w$-values) with various types and thicknesses of the filter material. Here only measurements were taken with $4 \mathrm{~cm}$ pipes with 1,2 and 5 sheets of glass fibre and with $1 \mathrm{~cm}$ of glass wool (so-called Mefi-filter). From the figure it is obvious that the influence of the thickness of the filter is rather large.

\section{Discussion of the results}

In the practical range of hydraulic conductivities of backfill material (up to some $10 \mathrm{~m} /$ day), the relation between entrance resistance and hydraulic conductivity can be considered as giving a straight line on $\log -\log$ paper, thus:

$m_{2}=a K^{-b}$

All the lines of Fig. 4, 5 and 6 have slopes between -0.9 and -1.1 and as a good estimation $b$ can be chosen equal to one, which means that equation 1 is valid. Now 
all effects can be characterized by the $a$-value which can be taken from the figures. The results are given in Table 1 .

Table 1 Resistance coefficients of plastic drainage pipes with various numbers of longitudinal slits and various filter materials

\begin{tabular}{cccc}
\hline $\begin{array}{c}\text { Diameter } \\
(\mathrm{cm})\end{array}$ & Rows of perforations & Filter & a-value \\
4 & 2 & 1 sheet of glass fibre & \\
4 & 4 & idem & 0.150 \\
4 & 8 & idem & 0.110 \\
4 & $\infty$ & idem & 0.090 \\
4 & 2 & idem & 0.066 \\
5 & 5 & idem & 0.150 \\
7 & 7 & idem & 0.089 \\
4 & 4 & idem & 0.078 \\
4 & 4 & no filter & 0.110 \\
4 & 4 & 2 sheets of glass fibre & 0.445 \\
4 & 4 & 5 sheets of glass fibre & 0.078 \\
4 & 4 & 1 cm glass wool & 0.039 \\
& & & 0.020 \\
\hline
\end{tabular}

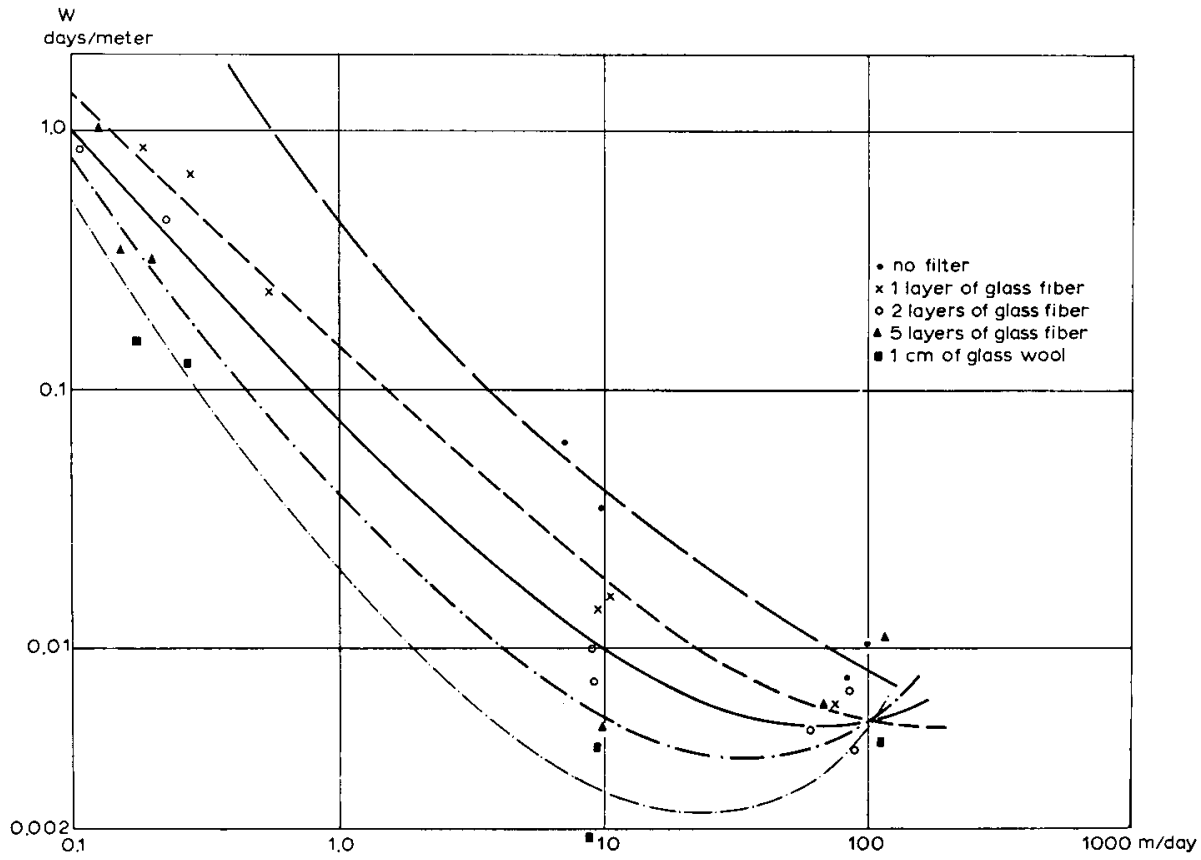

Fig. 6 Influence of various types of filter material on the w-value of $4 \mathrm{~cm}$ plastic drain pipes at various $K$-values of the soil. 


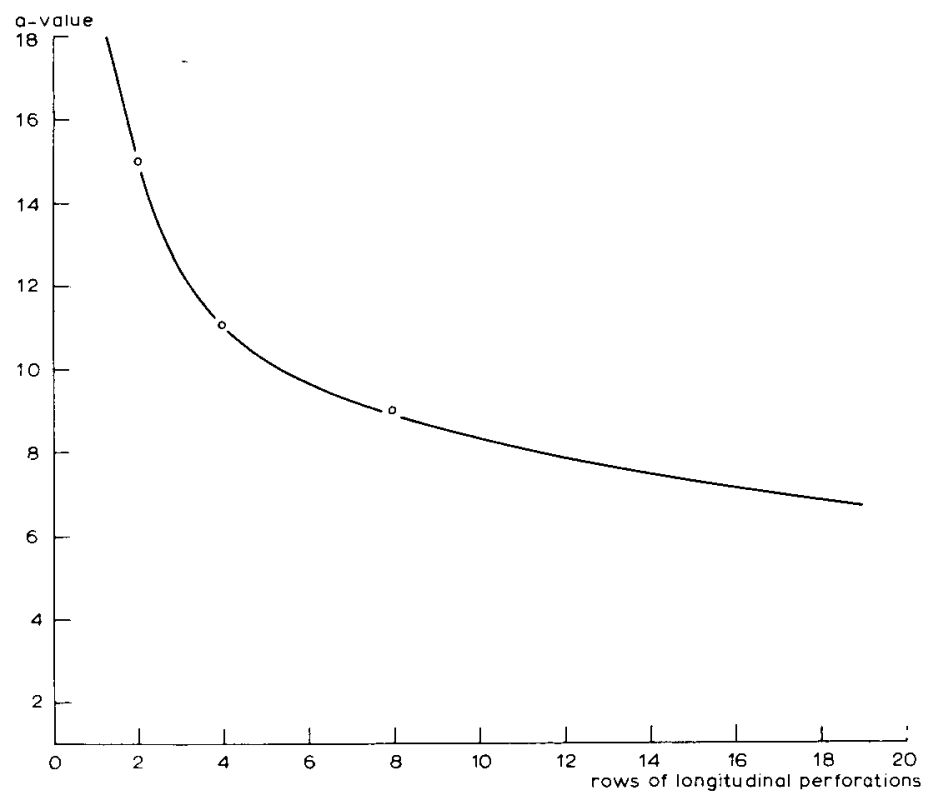

Fig. 7 Influence of the number of rows of perforations on the a-value (equation 1) of $4 \mathrm{~cm}$ pipes with a filter consisting of one sheet of glass fibre.

Table 2 Hydraulic head $(\mathrm{cm})$ required to overcome the pure entrance resistance according to equation 9 for a $4 \mathrm{~cm}$ pipe (spacing $15 \mathrm{~m}$, discharge $7 \mathrm{~mm} /$ day) with a filter of 1 sheet of glass fibre

\begin{tabular}{ccccc}
\hline \multirow{2}{*}{$\begin{array}{c}\text { Sof trench } \\
(\mathrm{cm} / \text { day })\end{array}$} & \multicolumn{4}{c}{ Rows of perforations } \\
\cline { 2 - 4 } & 2 & \multicolumn{2}{c}{4} & 8 \\
& & & & \\
10 & 6.1 & 4.1 & $(-)$ & 3.4 \\
50 & 1.5 & 0.9 & $(12)$ & 0.5 \\
100 & 0.5 & $0.25(4.5)$ & 0.1 \\
\hline
\end{tabular}

( ) $=$ without filter

Plotting the amount of rows of perforations against the computed $a$-values for $4 \mathrm{~cm}$ pipes with 1 sheet of glass fibre gives Fig. 7. The largest change in $a$-values is found between 0 and 4 rows. For more rows the change is rather small. This agrees with the results obtained by Boumans (1963) and van der Beken (1962).

No measurements with $7 \mathrm{~cm}$ pipes with a low amount of perforations have been carried out, but from the results obtained (compare Fig. 4 with Fig. 5 and take into account that for $4 \mathrm{~cm}$ pipes $w_{e}=0.9 \mathrm{w}$ ) it may be concluded that a larger diameter is more effective to lower the entrance resistance than a larger amount of perforations. From the data in Table 1 it is evident that even one sheet of glass fibre already 
reduces the entrance resistance considerably. Since this reduction occurs in all the used soil types, it may therefore be concluded that the effect of the filter is due to the forming of a layer with higher conductivity around the pipe, rather than to its effect as a filter.

Finally the conclusion can be drawn that thicker filters are even more effective than larger diameters or more perforations. As can be seen in Table 1, a $4 \mathrm{~cm}$ pipe with $1 \mathrm{~cm}$ of glass wool is more effective than a $7 \mathrm{~cm}$ pipe with 1 sheet of glass fibre. So giving a small pipe a thick filter is a better solution than taking a larger diameter, with the restriction, however, that this is only true if the filter will retain its high permeability under the prevailing field conditions.

\section{Practical conclusions}

First of all it can be asked what amount of perforations is needed for a plastic drain tube with a specific diameter. In order to get an answer to this question one can consider some practical cases. In The Netherlands the average spacing of a subsurface drainage system is some $15 \mathrm{~m}$. Taking as drainage criterion a design discharge of $7 \mathrm{~mm} /$ day, so $Q L \approx 0.1$, one arrives at the required hydraulic heads given in Table 2 .

Table 3 Hydraulic head losses (cm) over the last $3.5 \mathrm{~cm}$ from the centre of the pipe for drainage systems with pipes of various diameter

\begin{tabular}{|c|c|c|c|c|c|c|}
\hline \multirow{4}{*}{$\begin{array}{c}K \text { of trench } \\
(\mathrm{cm} / \text { day })\end{array}$} & & \multicolumn{5}{|c|}{ Diameter $(\mathrm{cm})$} \\
\hline & & \multicolumn{3}{|c|}{4} & 5 & 7 \\
\hline & \multirow[b]{2}{*}{ rows: } & \multicolumn{2}{|c|}{$\begin{array}{l}\text { I sheet } \\
\text { of glass fibre }\end{array}$} & \multirow{2}{*}{$\begin{array}{c}1 \mathrm{~cm} \\
\text { glass wool } \\
4\end{array}$} & \multicolumn{2}{|c|}{$\begin{array}{l}\text { l sheet } \\
\text { of glass fibre }\end{array}$} \\
\hline & & 2 & 4 & & 4 & 4 \\
\hline 10 & & 13.1 & 10.0 & 5 & 8.0 & 7.0 \\
\hline 50 & & 2.8 & 2.1 & 0.5 & 1.6 & 1.4 \\
\hline 100 & & 1.5 & 1.1 & 0.2 & 0.8 & 0.7 \\
\hline
\end{tabular}

Accepting a loss in hydraulic head of $5 \mathrm{~cm}$ as a tolerable value, one arrives at the conclusion that a perforation of 2 rows or $450 \mathrm{~mm}^{2}$ per meter is sufficient for most soils except in the case of a very low hydraulic conductivity in the trench. It has to be stated that without a filter more perforations are needed. For a 4 row perforation the data without filter are given between brackets.

For the determination of the effect of the diameter, again some calculations can be made. Under the same circumstances as given in Table 2 the extra loss of hydraulic head due to the entrance resistance can be computed. For this case, however, it is better to take equation 10, which gives the results given in Table 3.

Here the allowed value of a loss in hydraulic head of $5 \mathrm{~cm}$ will be reached with $1 \mathrm{~cm}$ of glass wool only if the hydraulic conductivity of the trench is $10 \mathrm{~cm} /$ day. In soils where the backfill is expected to have a low permeability it is worthwhile to use either more filter material or a larger diameter. 


\section{References}

Beken, A. van der, 1962. De aanwending van plastic bij drainage. Mimeograph Rijkslandbouwhogeschool, Gent.

Boumans, J. H., 1963. Over instroming en aanstroming bij drainbuizen zonder en met afdekking. Cultuurtech. Tijdschr., 2 : 218-229.

Engelund, F., 1953. On the laminar and turbulent flows of ground-water through homogeneous sand. Trans. Danish Acad. Tech. Sci., 5, 64 pp.

Ernst, L. F., 1954. Het berekenen van stationaire grondwaterstromingen welke in een vertikaal vlak kunnen worden afgebeeld. Rapport IV. Landbouwk. Proefsta. Bodemk. Inst. T.N.O., Groningen. (Mimeograph)

Ernst, L. F., 1962. Grondwaterstromingen in de verzadigde zone en hun berekening bij aanwezigheid van horizontale evenwijdige open leidingen. Versl. Landbouwk. Onderz., 67.15, $189 \mathrm{pp}$.

Hooghoudt, S. B., 1940. Bijdragen tot de kennis van enige natuurkundige grootheden van de grond. 7. Algemene beschouwing van het probleem van de detailontwatering en de infiltratie door middel wan parallel lopende drains, greppels, sloten en kanalen. Versl. Landbouwk. Onderz., 46 (14) : 515-707.

Jager, A. W. de, 1960. Diameter en perforatie van plastic drainbuizen. Ingenieur, 72B : 167-172.

Kirkham, Don., 1950. Potential flow into circumferential openings in drain tubes. J. Appl. Phys., $21: 655-660$.

Kirkham, Don. and Schwab, G. O., 1951. The effect of circular perforations on flow into subsurface drainage tubes. Agr. Eng., 32: 270-274.

Kozeny, J., 1933. Über den Wasserzudrang bei Dränfügen. Wasserkraft Wasserwirtsch., 28 : 13-17.

Someren, C. L. van, 1964. De toepassing van plastic draineerbuizen in Nederland. Cultuurtechniek, $2: 1-23$.

Wesseling, J., 1959. Enige resultaten van het onderzoek naar de perforatie van plastic draineerbuizen. Rept. I.C.W., Wageningen. (Mimeograph) 